\title{
The Difficulties and Strategies of Social Organizations Participating in Urban Community Governance
}

\author{
Xianliang He \\ Anji College of Zhejiang Open University, Huzhou, China \\ Email: zwy950120@163.com
}

How to cite this paper: He, X.L. (2021) The Difficulties and Strategies of Social Organizations Participating in Urban Community Governance. Open Access Library Journal, 8: e7613.

https://doi.org/10.4236/oalib.1107613

Received: June 4, 2021

Accepted: July 9, 2021

Published: July 12, 2021

Copyright $\odot 2021$ by author(s) and Open Access Library Inc.

This work is licensed under the Creative Commons Attribution International License (CC BY 4.0).

http://creativecommons.org/licenses/by/4.0/

(c) (i) Open Access

\begin{abstract}
With the continuous development and progress of society, social needs and social problems are also constantly appearing, which also puts forward new requirements and challenges for urban community management. Urban communities need diversified governance entities to participate in governance. As one of the governance entities of urban communities, social organizations participate in the governance of the community is an inevitable development trend. However, social organizations still have many problems and difficulties in the process of participating in urban community governance. Therefore, in the process of participating in urban community governance, social organizations must analyze the problems and difficulties in urban community governance based on the actual situation of the community, must continuously improve the systems and strategies for social organizations to participate in urban community management, improve the quality and efficiency of urban community governance, and maintain the health and stability of the community.
\end{abstract}

\section{Subject Areas}

Statistics and Econometrics

\section{Keywords}

Urban Community Governance, Social Organizations, Governance

Difficulties, Solutions

\section{1. 引言}

社区治理作为社会基层治理的组成部分, 对于国家的治理能力以及治理 
体系有着较高的要求, 社区治理的新型格局就需要多元化的治理主体共同参 与, 社会组织参与社区治理也成为社区治理的发展趋势。随着经济与社会的 发展, 人民的社会需求也不断增加, 社会问题也层出不穷, 政府在进行社区 治理方面存在一定的局限性, 为了更好地进行城市社区管理, 社会组织作为 具有自愿精神的管理主体, 与城市社区治理之间存在的依存性, 可以帮助城 市社区满足不同的社会需求, 更好地解决相应社会问题, 从而提升城市社区 管理的效果。一场突如其来的新冠肺炎疫情由于社会及媒体的持续发酵而进 入公众视野。疫情发生后, 各级政府迅速投入人力物力并实行强制性管制措 施, 战 “疫” 取得了阶段性成果。同时, 大多数人们也第一次看到了社会组 织在公共危机中的作用与能力。平日里, 他们各司其职, 默默充当社会运行 的润滑剂; 危难时, 尽管面对种种困难与问题, 各类社会组织大多尽其所能, 深入基层一线, 凝聚成一股坚实的抗 “疫” 力量。例如, 浙江马云公益基金 会捐赠 1 亿元用于支持新型冠状病毒疫苗的研发; 浙江公羊会公益救援促进 会成立突击队前往湖北, 对黄冈市红十字会、疫情防控指挥部、翡翠城小区、 惠明医院、物资接收点、医疗队入住酒店等多处设施进行消杀作业; 乐清蓝 天救援服务中心、温州黑马救援服务中心、瓯海海鹰救援队等 70 支应急救援 队伍共组织 1.28 万志愿者驰援交通、公安、城管等部门, 在高速口、动车站、 通乡干道、农贸市场设卡排查, 实施闭环管控; 安吉县 230 多家社区社会组 织组织志愿者深入社区开展重点人群的地毯式排摸、结对服务和 24 小时轮流 职守测体温等工作; 德清县心理协会联合多家社会组织共同组建“心理危机干 预热线” 志愿者服务小组, 主动为隔离人员和一线医疗人员提供心理援助服 务, 等等。如何更好地发挥社会组织在公共危机中的作用, 做到 “人尽其才, 物尽其用”, 是提升我国城市治理水平的重要议题。

\section{2. 社会组织参与城市社区治理的困境}

\section{1. 资金困境}

要做好城市社区治理, 社会组织就要与持续发展的可能性, 资金是维持 社会组织持续发展的基本。但是当前我国政府与社会对于社会组织运行资金 的确定性与稳定性较低, 在这样的资金条件下, 如果出现资金链的断裂, 社 会组织的发展与生存就会受到较大的影响。根据某基金会的《疫情背景下社 会组织生存状态调查报告》显示, 政府部门的投入在社会组织收入方面占据 首要地位, 190 家社会组织从政府部门获取资金支持, 其中 166 家以政府支持 为最重要的资金渠道。相反, 仅有 40 家组织表示能够依靠经验所得来 “自我 造血”, 而这其中主要依靠自身经营的机构少之又少, 仅有 14 家。同时社会 组织内部对于资金的管理也存在一定的问题, 部分组织对于不符合组织目标 的资金情况了解不够, 不能及时的放弃进而止损, 这对于社会组织参与城市 社区管理以及促进自身的健康稳定发展都有着一定的影响[1]。

\section{2. 用人困境}

社会组织在近年来进行城市社区治理的过程中, 在一些项目的运作以及 相关活动的开展方面存在着一定的问题, 尽管教育序列当中有社会工作专业, 
但所学与社会工作实际需要还是有较大的距离, 有针对性差、实操性弱的倾 向, 不太适应门类繁多、专业混杂的社会工作需要。特别是一些专业性较强 的领域中, 人才储备与工作的开展不匹配, 导致很多时候都要从各个其他的 部门进行人员的抽调, 部分人员在参与工作的过程中也非常的被动。仅就社 区而言, 老年人、妇女、儿童、残疾人、失业人员、农民工、服刑人员未成 年子女、严重精神障碍患者、有不良行为青少年、社区矫正人员等等, 每一 类的服务都需要专业知识, 如果没有专业人员, 即使建立了相应的社会组织, 功效也十分堪忧。同时社会组织的人才队伍发展与社会服务需求之间也存在 着较大的差距, 在已有的人才队伍中人才的知识结构存在不合理的情况, 大 部分人都是来自各行各业、各种专业背景或无任何专业背景, 只能边干边学, 对于组织的专业化管理程度较低, 并且组织内存在人员流动性较大, 这对于 社会组织参与城市社区管理造成了一定的困难。

\section{3. 经验困境}

成功的经验以及有益的范例可以为后期的发展提供借鉴。但是在社会组 织参与城市社区管理的过程中, 缺乏科学整体的布局, 同时社会组织的社会 服务水平与质量的提升也非常重要, 对社区居民的管理监督以及教育与自我 服务等多方面的提升都处于探索的阶段, 由于缺乏相应的经验, 组织管理的 方式与模式也较为单一, 并且在管理过程中存在较大的不确定性, 这必然会 对社会组织进行城市社区治理的效率与质量带来影响。

\section{4. 政策与制度的不完善}

社会组织作为社会的组成部分, 社会组织在进行城市社区管理中的外部 条件对于社会组织的治理效果以及自身的发展都有着非常大的影响。目前我 国关于社会组织的主要法律法规有: 《社会团体登记管理条例》 《民办非企业 单位登记管理暂行条例》《基金会管理条例》《社会团体登记管理条例》《长 办非企业单位登记管理暂行条例》 《关于改革社会组织管理制度促进社会组 织健康有序发展的意见》。面对较为复杂的社会环境以及社区居民需求, 国 家的政策支持对于社会组织参与社区治理的影响不容忽视, 政策制定的不完 善对于社会组织发展会造成较大的不利影响。同时, 社会组织自身也要加强 管理制度以及管理机制的建设与完善, 才能有效的提升社会组织在城市社区 管理中的作用, 促进治理水平与质量的提升[2]。

\section{5. 参与意识薄弱}

人民群众作为社区治理的主要对象, 在社会组织开展社区管理的过程中 有着非常重要的作用。随着人民生活水平的提升以及生活方式的改变, 社区 也逐渐趋向商业社区的发展, 特别是存着电子科技以及电商平台的发展, 人 们足不出户可以解决非常多的生活问题, 在这样的影响下, 人们之间的亲密 度也逐渐降低, 人民群众参与社区治理的参与度也大幅度下降, 很多人民群 众都只关注自己或者与自己利益相关的事情, 人们之间的信任度也较低, 因 此导致很多社区居民对社区治理表现的非常漠视甚至排斥。在这样的情况下, 
社区群众的真实社会需求无法被社会组织了解, 从而影响到社会组织参与城 市社区治理的治理效果。

\section{3. 社会组织参与城市社区治理的内部对策}

\section{1. 加强社会组织人才培育}

在城市的社区治理过程中, 政府可以将更多的社会公共服务项目给予社 会组织, 改善单一的社区治理结构, 提升社区治理的效果。因此社会组织一 定要加强自身能力的提升, 组建高素质的专业团队, 解决社会组织在城市社 区治理过程中存在的人才困境。社会组织要提升人员准入的门槛, 吸收引进 具备专业技能以及综合能力的高素质人才, 同时加强内部员工的能力提升, 定期组织相关的实践技能培训, 通过培训与考试, 让社会组织参与城市社区 管理的人员具备相应的技能以及证书等方式, 提升社区治理人员的专业能力 以及综合素质, 确保社会组织工作人员具备较高的技术水平与业务能力, 进 而提升社会组织治理城市社区的水平, 从而提供高质量的社区服务。

\section{2. 搭建治理平台}

社会组织参与城市社区管理中, 可以通过搭建城市社区治理的综合性服 务平台, 从而为社区居民提供更加细致并多样的社区服务。社会组织可以借 助飞速发展的电子科技与网络技术, 以及信息化的城市管理, 建立起社区治 理的综合服务平台, 将社区中的每一位居民通过网络联系起来, 结合当前的 大数据信息的发展, 建立数据服务体系, 进行社区资源信息的进一步整合, 实现社区资源与信息的共享, 让居民能够通过服务平台表达自身的真实需求, 让社区服务更加精确细致, 同时打破社会组织在开展城市社区治理工作中的 部门信息壁垒, 实现信息的同步共享, 提升社区服务的质量与效率。

\section{3. 构建健全完善的治理机制}

社会组织参与城市社区管理的过程中一定要加强独立、平等、自主的多 元化治理理念, 根据政府的方针政策要求, 构建健全完善的社区治理机制, 根据社区的具体情况以及社会组织所负责的社区服务与社区治理内容, 加强 治理体系与制度的建设。社区要充分的了解社区中不同利益主体的不同利益 需求, 根据相关制度, 进行利益的整合, 从而有效的化解矛盾、解决困难。 在进行治理机制制定中, 社会组织要提升居民的协商与议事能力, 构建协商 机制, 通过协商解决利益冲突与利益整合的问题, 实现不同利益主体的共赢。 同时要做好社会组织内部的权责划分, 明确每一个岗位的职责, 并结合奖惩 制度, 提升社会组织在城市社区治理中的治理水平与质量, 让社会组织充分 发挥其作用。

\section{4. 社会组织参与城市社区治理的外部对策}

\section{1. 加强与政府的合作, 开源节流}

社会组织要参与进城市社区治理, 首先要保持自身的稳定长期发展, 资 
金作为社会组织的生存发展基础, 解决资金问题也是社会组织参与城市治理 的首要问题。因此社会组织要学会加强与政府之间的合作与交流, 及时的了 解政府的相关政策, 在保持组织自主权和独立权的基础上, 巧妙的与政府合 作, 得到政府的资金与政策支持。政府也要通过招标等方式, 篮选优秀的社 会组织, 通过政府购买服务、设立项目资金、补贴活动经费等措施, 加大对 社会组织参与城市社区治理的扶持力度[3]。

\section{2. 提升群众参与}

针对社区居民对于社区治理活动参与度较低的问题, 社会组织就要进行 社区居民社会意识以及社区意识的培养, 提升社区群众的社区归属感以及社 区责任感, 同时要加强对于社区治理的宣传, 让社区居民正确的认识社会组 织以及社会组织管理下的城市社区治理活动, 降低群众对于社会组织的误解。 其次社会组织要不断的提升自身的社区治理水平以及社区服务质量, 真正的 解决社区群众的需求问题, 与社区群众建立起良好的信任关系, 让社区居民 积极主动的参与进社区治理工作中。社会组织还要积极的开展多种形式的社 区治理宣传, 让社区群众加深对于社区治理工作以及项目的了解, 深刻认识 到社区治理与自身利益之间的关系, 从而发现自身可以参与的社区治理项目, 挖掘群众的力量, 提升群众对于社区治理的参与意识。通过提升社区群众的 治理参与意识以及参与度, 实现全民治理, 促进社会组织治理社区的效果 [4]。

\section{3. 加强法治建设, 明确权责管理}

社会组织在进行城市社区管理时, 由于社会组织的发展状态还不够完全, 因此法律法规在进行社会组织的相关功能定位、资金、以及权责等方面的界 定不够清晰准确, 导致社会组织在进行城市社区治理的过程中无法遵循相关 规定, 且社会组织受到权益损失时维权也较为艰难。因此政府要加强有关社 会组织的法治建设, 从具体的法律法规中明确社会组织的各项行为活动, 让 社会组织参与城市社区管理工作能够更加的规范, 并实现制度化与法制化。 并且要加快相关法律法规的制定与出台, 取消冲突政策, 建立起完善的社区 治理管理体系。同时要保障社会组织参与城市社区管理的实现, 就要建立权 力、义务以及责任清晰的管理方式, 明确政府组织与社会组织之间的关系, 并实现权责利三方面的统一, 进而促进社会组织有效的参与城市社区治理。 社会组织还可以在社区组织法治讲座, 加强社区治理的相关法制宣传, 增强 群众的法治意识[5]。

\section{5. 结束语}

在社会的不断发展下, 城市社区治理也逐渐趋向于多元化, 社会组织参 与城市社区治理可以提升社区治理的灵活性与精确性, 但也应该看到, 社会 组织在参与城市社区治理的过程中存在着一定的问题, 尤其是忽视了社会组 织是加强和改进城市治理的重要参与者与实践者, 忽视了社会组织在城市治 理中的主体性和创造力。因此在城市社区治理过程中要充分激发社会组织活 力, 发挥社会组织参与城市治理的积极性、主动性、创造性, 实现政府治理 
与社会自治良性互动, 推进城市治理创新, 打破政府唱 “独角戏” 的格局。 同时加强组织人才的培育, 搭建相应的社区治理平台, 构建健全完善的治理 机制, 提升社区群众的参与度, 并加强法制建设, 明确责权制度, 不断地提 升社会组织参与城市社区治理的效果。

\section{课题项目}

本文系浙江省现代远程教育学会 2020 年度课题研究成果(课题编号: DES-20Z09)。

\section{Conflicts of Interest}

The author declares no conflicts of interest.

\section{References}

[1] 张君娜. 社会组织参与社区治理的实践困境及优化路径 [J]. 城市建设理论研究 (电子版), 2019, 287(5): 209.

[2] 郭旺仙. 当前城市社区治理的困境及创新路径[J]. 江南论坛, 2020(2): 33-34.

[3] 林士登. 社会组织参与社区治理研究 [J]. 管理观察, 2019, 10(3): 96-97.

[4] 宋雄伟. 社会组织参与城市社区治理的制度环境与行动策略 [J]. 江苏社会科学, 2019(2): 155-164.

[5] 于海利, 李全利. 社会组织参与社区治理的实践困境及优化路径 [J]. 中国国情国 力, 2019(4): 27-30.

\section{Appendix (Abstract and Keywords in Chinese)}

\section{社会组织参与城市社区治理的困境与策略}

摘要: 随着社会的不断发展进步, 社会需求与社会问题也不断地出现, 这对于城市的社区管理也提出了新的要求与挑战。城市社区需要多元化的治 理主体共同参与治理, 社会组织作为城市社区治理主体之一, 参与进社区的 治理是必然的发展趋势。但是社会组织在参与城市社区治理的过程中还是存 在着较多的问题与困难, 因此社会组织在参与进城市社区治理的过程中要根 据社区的实际情况，分析城市社区治理中存在的问题与困境，不断的完善社 会组织参与城市社区管理的制度以及策略, 提升城市社区治理的质量与效率, 维护社区的健康稳定。

关键词: 城市社区治理, 社会组织, 治理困境, 解决对策 